\title{
An epistemological framework for nanoscience and nanotechnology literacy
}

\author{
Robert M. Yawson
}

(C) Springer Science+Business Media B.V. 2010

\begin{abstract}
The need for a new literacy that will allow for meaningful participation in the rapidly evolving field of nanotechnology is very critical to national development. This need is important for nanotechnology to achieve its full potential. This paper describes and analyzes some contemporary philosophical interpretations of the concept of technological literacy. The paper then focuses on some of the metaphysical assumptions underpinning the techno-scientific literacy framework; and theories governing public understanding of science and technology, as the basis to propose a new technological literacy framework suitable in the era of nanotechnology. A case is made that the new technological literacy framework proposed is a suitable and essential pedagogic endeavour which should be seen as yielding a perspective through which meaning may be infused into the importance of nanotechnology development-a perspective as essential to the informed lay person as it is to the truly literate technologist. The paper concludes by analyzing the implications of the proposed epistemological framework on nanotechnology workforce development and makes recommendations based on this new framework to achieve a 'nanoliterate' society.
\end{abstract}

Keywords Epistemology · Nanoliteracy · Systems dynamics modeling ·

Workforce · Triple Helix · Curriculum

\section{A case for a new technology literacy framework}

Currently knowledge on nanotechnology and nanoscience is generally fragmented and disjointed even within the academic community (Toumey and Baird 2006). Despite its trans-, inter-, and multidisciplinary nature, learning of nanotechnology is currently situated within disciplines (Schummer 2004). Technical aspects of nanotechnology with little to nothing about its societal and ethical questions are learnt by scientists and engineers, both students and academic staff. The same can be said of humanists and social scientists, who

R. M. Yawson $(\bowtie)$

Department of Organisational Leadership, Policy, and Development, College of Education and Human Resource Development, University of Minnesota, 330 Wulling Hall, 86 Pleasant Street SE,

Minneapolis, MN 55455, USA

e-mail: yawso003@umn.edu 
are studying the societal and ethical issues, but on the most part poorly literate in the underlying science. This definitely does not portend well for the development of the technology if those within the academic community restrict themselves to constricted, disarticulated perspectives on nanoscience and nanotechnology. In order to bridge the knowledge gap to better educate tomorrow's nanotechnology workforce, there is the need to build 'nanoliteracy' within academe and beyond (Toumey and Baird 2006).

In the words of Dakers (2006, p. 1):

We are transforming our world at an alarming rate and in so doing, we are alienating ourselves from it. Our technologically mediated existence is threatening the very democratic process itself. We need to develop a new language, a new literacy, in order to both understand our brave new world, and learn how to live a meaningful existence in it.

This paper discuses the need for this new literacy (nanoliteracy) that will allow for meaningful participation in the rapidly evolving field of nanotechnology. A case is made as to how the nanoliteracy framework is a suitable and essential pedagogic aim yielding a perspective through which meaning may be infused into the importance of nanotechnology development-a perspective as essential to the informed lay person as it is to the truly literate technologist (Liddament 1994). This need is important for nanotechnology to achieve its full potential; very critical for nanotechnology workforce development; and important for national development. Contemporary philosophical (a critical realist ontology and epistemology) interpretations of the concept of technological literacy are discussed as a basis to propose a new framework suitable in the era of nanotechnology. The underlying theme of this paper is epistemological, since it seeks to answer the question: what kind of literacy will allow for meaningful participation in the rapidly evolving field of nanotechnology, and what is the rational basis of such knowing and telling? This new epistemological framework is then discussed in the context of nanotechnology workforce development.

Nanotechnology: the next industrial revolution

Nanotechnology has been described by scientists, policy makers, and business leaders as the beginning of the next great industrial revolution. It has been "hailed as the first technological revolution of the twenty-first Century which will support economic growth whilst helping to solve some of society's greatest challenges" (RCUK 2010 webpage). The transformation nanotechnology is expected to make to society has been predicted to exceed the impact that information and communication technology has had over the past 30 years. According to the Project on Emerging Nanotechnologies of the Woodrow Wilson International Centre for Scholars, "an estimated global R\&D investment of nearly $\$ 9$ billion per year is anticipated to lead to new medical treatments and tools; more efficient energy production, storage and transmission; better access to clean water; more effective pollution reduction and prevention; and stronger, lighter materials" (PEN 2010, p. 1). These are just a small portion of the advances and anticipated uses of the technology.

Applications of nanotechnology are in it nascent stages and has only just started to make an impact on the market. The U.S. National Science Foundation (NSF) has predicted that the total global market for nanotechnology products and services will reach $\$ 1$ trillion by 2015 (NNI 2009). RNCOS Consulting (2010) gives even a higher estimate: According to their forecast, the global market for nanotechnology incorporated in manufactured goods will worth US\$ 1.6 Trillion, for the period 2010-2013. This prospective growth will 
largely be driven by massive investment in nanotechnology research and development by both governments and corporate entities worldwide.

There are several definitions of nanoscience and nanotechnology in the literature. Many of these definitions are derived by government agencies and have been modified with the passage of time to include the concerns and interests of society as a whole, as expressed through the technological, commercial, populist, legal, social, and ethicist communities (Romig et al. 2007). The most cited definition of nanotechnology is that of the National Nanotechnology Initiative of the United States: "Nanotechnology is the understanding and control of matter at dimensions between approximately 1 and 100 nanometres, where unique phenomena enable novel applications. Encompassing nanoscale science, engineering, and technology, nanotechnology involves imaging, measuring, modelling, and manipulating matter at this length scale" (NNI 2009 webpage). A nanometre is onebillionth of a metre. To put this measure in perspective using a sheet of paper as an analogy: The thickness of a sheet of paper is approximately 100,000 nanometres thick. The dimensions between approximately 1 and 100 nanometres are the nanoscale (NNI 2009). At this scale, unusual physical, chemical, and biological properties can emerge in materials. These properties tend to differ in very significant ways from the normal properties of bulk materials and single atoms or molecules (NNI 2009).

In this nascent era of nanotechnology, there is a growing need for individuals and societies, to be more critically involved in the dialogue surrounding nanotechnology. There is the need for a technology literacy that will empower people to improve their world in a creative, sensitive, informed and above all, sustainable fashion to curtail any tensions or confusions that may arise between humanity, and its environment, as a result of the advances in nanotechnology. The following section discusses the contemporary ontological and epistemological analysis of technological literacy, to serve as the basis for the new epistemological platform proposed in this paper for nanoliteracy.

\section{Contemporary philosophical interpretations of the concept of technological literacy}

The rigour of the philosophical basis underpinning technology literacy has received its fair share of critical attention and there have been countless efforts to define it over the years. A great deal has been written on the history and philosophy of the concept of 'technological literacy' (e.g. Dyrenfurth 1991; Hayden 1989; Jenkins 1997; Lewis and Gagel 1992; Petrina 2000; Selfe 1999; Todd 1991; Waetjen 1993). Over the past decade and half a new concept described as 'emancipatory technoliteracies' has begun to emerge (Kahn and Kellner 2005). However, contemporary discussions have been skewed to information and communication technologies and have not been placed within the broader context of all technologies and also devoid of the current debate concerning the epistemology of practical knowledge. This limited portrayal of the scope of technological literacy may, perhaps, partly be as a result of a marginal and increasingly narrow handling of technology in the school curriculum; and also, how it has been situated as a discipline.

This paper is not seeking to reproduce yet another account of the same. However, it is important to briefly discuss the meanings that 'technology' and 'technology literacy' have received considering that tremendous variance exists in the literature with the description and the philosophy of technology. Moreover, to understand the various philosophical descriptions of technology literacy might well begin with philosophical definitions of 
technology. This is an attempt towards achieving an understanding which will serve as the basis of the new framework this paper is proposing.

What is the philosophical meaning of technology?

Dugger (2000) described technology as consisting of all the changes humans have made in the natural environment for their own interests and purposes. The United States National Academies broadly defined technology as "any modification of the natural world made to fulfil human needs or desires" (Gamire and Pearson 2006, p. 1). They had earlier broadly described technology as "comprising the entire system of people and organizations, knowledge, processes, and devices that go into creating and operating technological artefacts, as well as the artefacts themselves" (Pearson and Young 2002, p. 3). Technology is pervasive and it includes a countless number of devices and systems that greatly affect every individual in society. It is therefore critical for an informed citizenship to be familiar with what technology is, how it is created, how it works, its societal implications and how it shapes society, and the different societal influences on technological development (Gamire and Pearson 2006).

Ihde (1990) positioned technology within a context far beyond the limitations of the material artefacts that many identify as its boundary. The multidimensional concept of technology by Ihde has a broad support in the literature (Gagel 2006). Feenberg (1999, p. xii) discussed technology in the context of power, control, and politics, but at the same time recognized the more physical aspects of technology. He argued that the study of "technology as a total phenomenon...must include an experiential dimension since experience with devices influences the evolution of their design". As Gagel (2006) analogized, the plumber for example is a plumber because of the tools, materials, and processes used in the practice of the vocation. Feenberg (2006) presented the various alternatives of contemporary philosophical perspectives of technology as a matrix that clearly summarizes the discussion. The following section draws substantially from Feenberg's (1999, 2006) explanation of his matrix (Table 1).

From the variety of philosophies and theories, Feenberg defined technology along two dimensions in relation to values and agency. The vertical dimension of the matrix makes provision for two options: the typical contemporary assumption that technology is valueneutral; or the Grecian belief, which some philosophers still ascribe to today, that technology is value-laden. The difference between these alternative views may not be apparent to the casual reader. On the horizontal dimension technologies are presented as either autonomous or humanly controllable. Feenberg (2006, p. 10) explained that:

To say that technology is autonomous is not of course to say that it acts alone. Human beings are involved, but the question is, do they actually have the freedom to decide how technology will be applied and develop? Is the next step in the evolution of the technical system up to human decision-makers or do they act according to a logic inscribed in the very nature of technology? In the latter case technology can

Table 1 Alternative definitions for technology (C) Feenberg $(1999,2006)$

\begin{tabular}{lcc}
\hline Technology is & Autonomous & Humanly controlled \\
\hline $\begin{array}{l}\text { Neutral (complete separation of } \\
\text { means and ends) }\end{array}$ & $\begin{array}{c}\text { Determinism (e.g. } \\
\text { modernization theory) }\end{array}$ & $\begin{array}{c}\text { Instrumentalism (liberal faith in } \\
\text { progress) }\end{array}$ \\
$\begin{array}{c}\text { Value-laden (means form a way of } \\
\text { life that includes ends) }\end{array}$ & $\begin{array}{c}\text { Substantivism (means and ends } \\
\text { linked in systems) }\end{array}$ & $\begin{array}{c}\text { Critical theory (choice of alternative } \\
\text { means-ends systems) }\end{array}$ \\
\hline
\end{tabular}


rightly be said to be autonomous. On the other hand, technology would be humanly controllable if we could determine the next step in its evolution in accordance with intentions elaborated without reference to the imperatives of technology.

Feenberg (2006) described the intersection of the two dimensions as defining four types of theories: Instrumentalist, determinist, substantivist, and critical theories. Instrumentalism is the 'standard' contemporary view of describing technology as a tool or instrument of entire humanity. The determinist view of technology is fixed partially in knowledge of nature and partially in generic features of humanity. "This is why it can be described as neutral, as a rationally constructed tool serving universal human needs" (p. 11). Substantivists ascribe substantive values to technology in contrast to instrumentalist and determinist views of technology being neutral. Critical theory of technology is the position that calls for the extension of democracy to technology. Critical theorists recognize the catastrophic intended and unintended consequences of technological development but still see a promise of future benefits of technology. For detailed analyses of these theories one may refer to the work of Feenberg $(1999,2006)$. The new epistemological framework proposed in this paper makes no attempt to situate nanotechnology in any of these philosophies, as it will be restrictive and create a bounded conception.

\section{What is technological literacy?}

The International Technology Education Association (ITEA) stated that technological literacy is "the ability to use, manage, understand, and assess technology" (ITEA 2000, p. 242; Rose et al. 2004, p. 1). The National Academies described technological literacy as encompassing "three interdependent dimensions of knowledge; ways of thinking and acting; and capabilities" (Gamire and Pearson 2006, p. 1). The underlining objective of technological literacy is to offer people with the tools to engage intelligently and conscientiously in the world around them. The knowledge dimensions of technological literacy can vary depending on the jurisdiction and the era. The Committee on Assessing Technological Literacy of the National Academies which described the three interdependent dimensions of technological literacy further explained the dimensions as follows (Gamire and Pearson 2006; Pearson and Young 2002):

1. Knowledge dimension is characterized by the combination of factual knowledge and conceptual understanding.

2. Capabilities dimension relates to how well a citizen can use technology as broadly defined and carry out a design process to solve a problem. They explained that a technologically literate individual should be able to use technologies and technological artefacts commonly found in the home or office and should be able to do basic troubleshooting when the need arises.

3. Critical thinking and decision-making dimension is how an individual approaches technological issues. That is, a person with well developed critical-thinking and decision-making skills should be able to ask relevant questions about risks and benefits of the technology being discussed and should be able to participate in discussions and debates about the uses of that technology.

Thomas and Knezek (1995) described technology literacy as more than the knowing of the current uses of technology, and more than one's ability to use common technologybased artefacts in accordance with a given instruction for realizing some explicit outcome. They explained that technology literacy involves: 
...demystifying technology through conceptual understandings of the underlying science and mathematics principles, operational competence with modern technology systems, the ability to evaluate and use a variety of common technology applications, the ability to innovate and invent ways of applying technology in challenging new situations, an awareness of technology-related careers and of factors critical to success in those careers, and understanding of and sensitivity to societal issues related to technology (Thomas and Knezek 1995, p. 1-2).

Braundy (2004) described how Dewey articulated the importance of technologically literate citizens and Dewey's emphasis on the importance of collective knowledge production in the making of thoughtful citizens with critical thinking abilities. Dewey at the turn of the past century practically defined technology literacy without actually using the terminology itself. He described how education could set up the fundamental understanding of the practice and producing to meet society's needs:

Unless the mass of workers are to be blind cogs and pinions in the apparatus they employ, they must have some understanding of the physical and social facts behind and ahead of the material and appliances with which they are dealing... What is wanted is that pupils shall form the habit of connecting the limited information they acquire with the activities of life, and gain ability to connect a limited sphere of human activity with the scientific principles upon which its successful conduct depends. (Dewey and Dewey 1915, p. 246-247).

In the era where demarcating disciplines has become an educational practice, such universal projects have become very scarce (Braundy 2004). These universal projects are however, critical in the era of nanotechnology. The multi-, trans- and interdisciplinary nature of nanotechnology are an indication that strict disciplinary demarcations in education practice may no longer continue to be the norm.

\section{Towards a new technological literacy framework in the era of nanotechnology}

The emergence of nanotechnology means that previously disparate disciplines are merging and converging at the nanoscale to develop novel applications and even novel life forms. Schummer (2004) described the predominance of interdisciplinarity as a core theme of nano-discourse. This technological and domain convergence is now so familiar a concept as to be given acronyms like GRAIN (Genetics, Robotics, Artificial Intelligence and Nanotech) and NBIC (Nano, Bio, Info, Cogno) (Roco and Bainbridge 2003). However, as mentioned in the introduction to this paper, despite the technological and domain convergence; the multi-, trans-, and interdisciplinarity nature; nanotechnology is still largely situated in demarcated disciplines. This calls for a new technological literacy framework: A framework that will encompass Science, Technology and Society (STS) literacy in general, environmental literacy, science literacy, and technology literacy as it exists today. The first and most fundamental conceptual issue concerns the scope of this technoscientific literacy framework. Given the strong likelihood that nanoscience and nanotechnology policy may remain within the normal democratic policy formulation process in most countries, it is important to develop a framework of civic technoscientific literacy suitable for the era of nanotechnology.

The review of the literature on the philosophical underpinnings of technological literacy shows that it has largely been restricted to technological education discipline and therefore, 
the debate has centred on the development of the relevant curriculum and the pedagogy to develop technological literate citizenry. Several of the philosophers and theorists have discussed technological literacy as a discipline instead of looking at it as a way of life as has been severally described. The danger in this is that nanotechnology, for example, may create a situation where in most industries, technologically illiterate unskilled workers will be displaced and see their standard of living and their very ability to earn a living eroded in the midst of significant technology-based economic success (Thomas and Knezek 1995). These displaced workers will not require a grade 7-12 curriculum (i.e. typical age at end of the school year ranging from 12-18 years) to become technologically literate. It is vital that the government positions itself for continued building among all its citizens capacity for understanding, coping with and applying emerging technologies (Thomas and Knezek 1995). Lifelong learning, media literacy, vocational education, inter alia, are all needed in creating a technological literate society.

The epistemological framework described in this paper therefore takes a completely different approach. The importance of school curriculum in the creation of technological literate citizens is not in dispute, what has been in dispute is the nature and type of curriculum that is needed. However, there is more to the creation of technological literate citizenry than the sole attribution to the relevant curriculum and pedagogy. From public acceptance of technology theories and related theories, this study has identified ten main factors that may have an impact on technological literacy. These factors are by no means exclusive and may have to be tested empirically to understand the magnitude of their impact. Figure 1 shows these factors. The diagram depicts a foundational platform for a future systems dynamics modelling of technological literacy. In a study to understand the underlying values, expressed attitudes and actual behaviours involving consumer acceptance of agrifood nanotechnology, Yawson and Kuzma (2010) ranked the impacts of most of these factors on public awareness of agrifood nanotechnology.

Systems dynamics modelling and simulation could be used as an effective tool for any formulation and understanding of experimental results as well as any metaphysical conceptualizations. Systems models give the chance for experimentation and reflection and thus can facilitate the complete understanding of the complex environment in which educational policy makers operate (Fisher et al. 2000). The epistemology of nanoliteracy as discussed so far involves a high level of complexity in which to model and to understand how practical and effective nanolitercacy can be implemented differently from many other areas of modern science and technology like biotechnology, gene editing technologies,

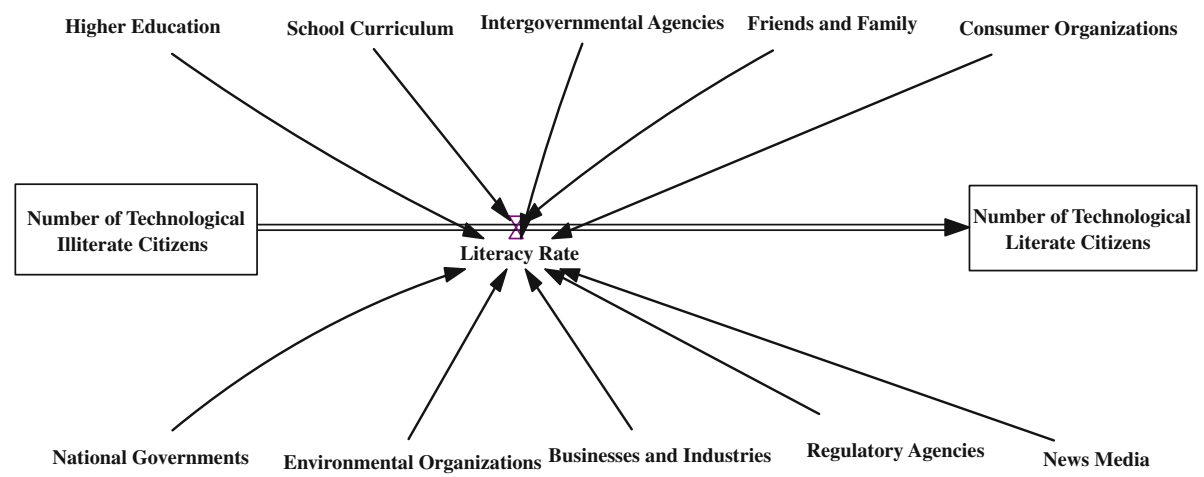

Fig. 1 Foundational systems map for a new technological literacy framework 
synthetic biology, among others. The complexity exists, partly due to the emergent as well as the multidisciplinary nature of nanotechnology (Yawson 2010). Nanotechnology unlike many of the other modern science and technology requires that:

Any curricula developed for nanotechnology should therefore be based on good theoretical foundations and a balance of knowledge competencies drawn from mathematics and the physical sciences together with the chemical and biological sciences integrated with applied sciences (particularly material science, microelectronics technology, and instrumentation technique, among others), commerce, management, social sciences and the humanities. (Yawson 2010, p 290)

This is what makes nanoliteracy a new and an important paradigmatic way of looking at STS literacy, environmental literacy, science literacy, and technological literacy. In the age of nanotechnology the various 'literacies' cannot be seen as disparate frameworks but all converging within nanoliteracy. That is why we need a new literacy framework. Policy makers and educators can therefore learn about the effectiveness of the policies to promote nanoliteracy through feedback within the system. Through system dynamics, policy makers and other stakeholders may gain insight into the causal factors that create technological illiteracy. Knowledge of how causal factors affect technoscientific literacy may assist industry, educators, academics, non-governmental organizations (NGOs) and policy decision-makers in strategic planning and how to tailor policies towards a nanoliterate society.

Another episteme platform for the new technological literacy being proposed is the relevant stakeholders and how they interact. There has been an increased level of interest by social scientists and humanists in analyzing the enterprise of science and technology (Mehta 2002). From the early 1950s, advances and developments in science and technology have driven major innovations and developments in nuclear technology, information and communication technology, biotechnology and recently nanotechnology and synthetic biology. In addition to driving innovation and stimulating convergence, these technologies have also created an urgent social need to analyze and understand the risks and benefits from such innovations, and have brought to the fore the relevance of technological literacy to the enterprise of science.

New theories, such as the 'Triple Helix' model and legislation like the Bayl-Dole's Act have generated an atmosphere of cooperation and how business must be done between different institutional actors and their roles in the creation, transfer and use of knowledge in a global system (Leydesdorff and Etzkowitz 1998). Although these theories were not proposed with technological literacy in mind they have similar ontological and epistemological underpinnings. The 'Triple Helix' is acclaimed to have a better understanding of how a complex and uncertain world operates in reality. It is three-dimensional in nature and brings together industry, academia and government, as the three helices. The Triple Helix is a dynamic system, and it is characterized by three variables: the economic dynamics of the market, the internal dynamics of knowledge production; and the governance at the interface of different levels (Leydesdorff and Etzkowitz 1998). However, critics of the triple helix theory have pointed out that the public is an essential fourth helix, which must be included. This is, even more so, as this discussion is centred on developing a technological literate public. Critics further argue that advances in emerging fields such as biotechnology, nanotechnology and synthetic biology are jeopardized by the virtual absence of this helix (Leydesdorff and Etzkowitz 2003). 
Some philosophers have therefore, proposed what they refer to as "the quadruple helix" which incorporates a fourth helix being the public (Leydesdorff and Etzkowitz 2003, Mehta 2002). Disciplinarity is no longer the overriding scheme for knowledge creation and organization (Mehta 2002). Knowledge creation is now trans-disciplinary, more reflexive, non-linear, complex, and hybridized (Yawson 2009) making the inclusion of the fourth helix extremely important. This is because the social robustness and inclusivity of scientific and technical knowledge determines the value of knowledge and how it can be used (Leydesdorff and Etzkowitz 2003). Public interest is important in this regard, because the whole concept of technology literacy is about a technologically literate society. The fourth helix highlights new discoveries and innovations brought about by nanotechnologies that improve social welfare. It helps to create linkages between science, scientists, public, and education strategies.

It is important, however, that in the era of nanotechnology a fifth helix is introduced: That is the separation of the public from advocacy groups and other NGOs. This study therefore, incorporates a fifth helix: a Quintuple Helix Theory as depicted in Fig. 2 in the form of a stakeholder map. From historical precedents especially in the case of biotechnology and genetically modified foods, the role of this fifth helix was very significant especially with regards to consumer acceptance and public perception. It is the contention of this paper that the level of technological literacy will affect public acceptance of emerging nanotechnologies.

Academia in this nanoliteracy map is not referring to only higher education but all levels and forms of education. Most philosophical discussions place grade 7-12 curriculum development as crucial for technological literacy (Ezziane 2007), which is an undeniable philosophical fact. However, the introduction of nanotechnology and nanoscience to the classroom brings with it different kinds of challenges. The multi-, trans-, and interdisciplinary nature of nanoscience and nanotechnology make them very different from the traditional disciplines contained in the current grade 7-12 curriculum. This requires removal of the curricular demarcations that exist between the science disciplines. The practice in schools where science tends to be taught with strict divisions between disciplines (Stevens et al. 2007) may need reformation with the advent of nanoscience. A persuasive argument can be made that the educational curriculum is already overcrowded and adding subject matter content (SMC) specific to nanoscience and nanotechnology will only serve to compound the situation. However, this argument is flawed

Fig. 2 A stakeholder map for nanoliteracy

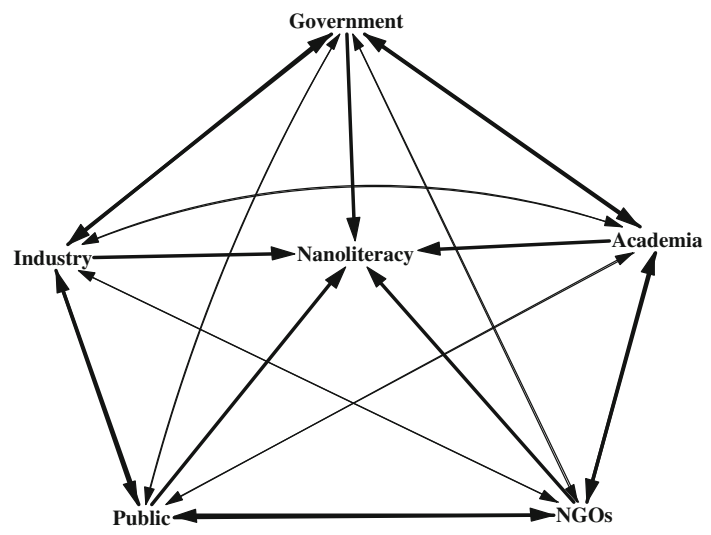


and shows how nanotechnology is misunderstood. In the first place the new literacy framework this paper is describing is not restricting nanoliteracy to curriculum development, neither is it calling for addition of SMC to the curriculum, but reformation of the curriculum. Moreover, nanotechnology cannot and should not be taught at the grade 7-12 as a specific subject but a concept encompassing all the various disciplines.

The arbitrary sequence with which disciplines are taught with little to no reference between them may have to change. Successful incorporation of nanoscience into grade 7-12 curriculum is also a challenge. It is necessary to first identify where it might be appropriate to introduce nanoscience concepts into the science curriculum in order to support student learning (Batchelor et al. 2009). Another challenge is professional development of teachers. The nascent and emerging nature of nanoscience and nanotechnology necessitates that teachers be introduced to new concepts and strategies and learn how to teach the traditional curriculum differently (Bryan et al. 2007) by finding and then communicating connections between the disciplines to the students.

\section{Technological literacy and nanotechnology workforce development}

The argument for a new technological literacy as laid out in this paper is based on one main fundamental principle: In a world anticipated to be transformed in several ways by a new technology paradigm, that will affect all facets of life and behaviour, the basic understanding of technology by an individual will be the principal factor that will determine how that individual functions more effectively. This is a clear indication of the need for technological literacy for all citizens. A higher level of technological literacy brings with it a number of benefits, for individuals and for society as a whole (Pearson and Young 2002). Workforce development is one area that will be positively influenced with high level of technological literate citizens.

Currently students in the U.S. public school systems lack strong math and science aptitude and these can pose a serious challenge and endanger the growth of a nanoworkforce (NSB 2010). In an assessment of the state of U.S. precollege education in the early 1970s, the National Science Board's (NSB) Commission on Precollege Education in Mathematics, Science and Technology found these fields wanting (Coleman \& Selby 1983). The Commission therefore made several recommendations and projected that U.S. precollege achievement should be best in the world by 1995. This goal has not been met and the situation seems to have stayed the same or even deteriorated as many other countries have surpassed the U.S. (NSB 2006). The era of nanotechnology demands an even more pressing need to build a new foundation.

Secondary school students have shown little interest in fields which develop and produce high tech goods (Fonash 2001). The way around this challenge of increasing awareness is nanoliterate school educators and counsellors (Fonash 2001). Educators and counsellors must appreciate the impact nanotechnology will have on society, appreciate what is needed to prepare the nanotechnology workforce, and successfully translate that to students and parents (Yawson 2010). Administrators and academic staff must be ready and take the required process to make the transition in a new technology paradigm. The role of industry, NGOs, government and the public itself cannot be discounted in this process. All factors that contribute to a technological literate population, prepares people for work or offers them an opportunity to improve their skills forms part of the workforce education system. 


\section{The way forward}

A new approach to technology literacy in this nascent era of nanotechnology is necessary for national well-being. If nanoliteracy is to be achieved, the following recommendations may have to be considered:

- Development of standards to address the science and mathematics of technology and to remove the existing curricula demarcations in the sciences within the overall framework of school curricula revision.

- Nanoliteracy should be established as a component part of all forms of adult education and worker retraining.

- Policies that place nanoliteracy on the national agenda for all citizens should be made a priority.

- National policies towards public understanding of science and public acceptance of nanotechnology; and risk, regulatory, and governance of nanotechnology should not be delineated from technological literacy policies. These policies should be formulated in a holistic manner. Public engagement strategies for risk communication for example should be incorporated into adult education curricular.

- Technological literacy should not be seen as a discipline, but as a "language of life" where every citizen will need to understand in order to be able to communicate.

- The undertaking to achieve a nanoliterate nation will depend on the collective roles of the education, business, public, NGOs, and policy-making communities as articulated in the "quintuple helix" described in the proposed nanoliteracy framework.

Nanoliteracy will prepare the public to make well-informed choices in their role as consumers of nanoproducts. As has been predicted by scientists, governments, and industries, and repeated several times in this paper, nanotechnology has brought the world to the verge of another industrial revolution and brings with it products and services that promise efficient and healthier lives; and these products are appearing on the market with an increasing pace. It is estimated that as of August 25, 2009, there were 1015 products or product lines on the consumer inventory list (PEN 2010). Nanotechnology has also been described as having potential negative consequences for human health and the environment, and several risk governance and regulatory policies are being formulated (Kuzma et al. 2008).

A nanoliterate person may not have the knowledge of how each nanotechnology product or application works, its risks and benefits, how to operate it, and so on, but it is expected from the proposed nanoliteracy framework that individuals will be literate enough about nanoproducts and services to ascertain the risk and benefits inherent in their use. The public(s) will not only be consumers; they will also continue to be workers, members of families and communities, and citizens of large, complex political and governance systems. As anticipated, in all of these spheres of life, there will be personal decisions that will involve the use of nanotechnology.

A critical challenge for nanoliteracy for all citizens is the problem of general adultilliteracy. A study by the National Centre for Education Statistics (NCES) in 2003 found that an estimated 32 million adults in the U.S. (one out every seven adults) are burdened with such low literacy skills that it would be impossible for them to read anything more challenging than a children's picture book or to understand a medication's side effects listed on a pill bottle (White and Dillow 2005). The NCES' National Assessment of Adult Literacy (NAAL) study showed that from 1992 to 2003, the USA added about 23 million adults to its population; in that period, an estimated 3.6 million more joined the ranks of 
adults with low literacy skills (NCES 2004). The importance of informal adult education, public engagement strategies, curriculum reformation among others as described in the new epistemological framework will help to meet this challenge.

In addition to the educational reform efforts to bring technology literacy to all learners, it is important to consider the new epistemological framework proposed in this paper. Most often, attempts at retraining fail to effectively educate workers in the area of technology (Thomas and Knezek 1995). The goal of the new epistemological framework proposed in this paper therefore presents specific challenges and demands a relook at curriculum reform; teacher education; adult education; intersection of regulatory, governance, STS, and risk policy formulation with technological literacy initiatives; and overall education policy formulation. As Waks (2006) aptly described: "Leaders in technological literacy education still remain committed to the paradigms established a quarter century ago" (p. 288). The prevailing STS, environmental and technological literacy education remain inadequate, inconsistent, and scattered (Hungerford and Volk 2003). Prevailing designs of technology literacy education ties technology-related learning to curriculum that is already established and essentially a component of high (secondary)-school curriculum (Waks 2006). In the era of nanotechnology the status quo cannot continue. The new literacy framework described calls for a more fundamental reconsideration of technology literacy. The era where STS, environmental, science, and technology literacy education are seen as disparate endeavours has to end.

Acknowledgments I would like to thank Prof. Kenneth R. Bartlett of the College of Education and Human Development, University of Minnesota for encouraging me in putting this paper together and his valuable critique of the final draft. I also thank Prof. Jennifer Kuzma of the Centre for Science, Technology and Public Policy, Hubert H. Humphrey Institute of Public Affairs, University of Minnesota, for awarding me an assistantship which enabled me to undertake this study.

\section{References}

Batchelor, R., Bryan, L., Bodner, G., Daly, S., Delgado, C., Fornes, W., et al. (2009). Introduction of emerging science into the classroom-the case of nanoscience and nanotechnology. The NanoEd Resource Portal. National Centre for Learning and Teaching of Nanoscale Science and Engineering Education (NCLT). Evanston, IL: Northwestern University.

Braundy, M. (2004). Dewey's technological literacy: past, present, and future. Journal of Industrial Teacher Education, 41(2), 20-36.

Bryan, L., Daly, S., Hutchinson, K., Sederberg, D., Batchelor, R., Hagedorn, E., Fornes, W., \& Giordano, N. (2007). A design-based approach to the professional development of teachers in nanoscale science. Paper submitted to the annual meeting of the National Association for Research in Science Teaching, New Orleans, Louisiana.

Coleman, W. T., Selby, C. C. (1983). Educating Americans for the 21st Century. Report of the National Science Board (NSB) Commission on Precollege Education in Mathematics, Science and Technology. Washington, DC: National Science Foundation, CPCE-NSF-04.

Dakers, J. R. (2006). Introduction: Defining technological literacy. In J. R. Dakers (Ed.), Defining technological literacy: Towards an epistemological framework (pp. 1-2). New York, NY: Palgrave Macmillan.

Dewey, J., \& Dewey, E. (1915). The schools of tomorrow. New York: E. P. Dutton \& Company.

Dugger, W. E., Jr. (2000). Phase III technology for all Americans project. Technology Teacher, 60(4), 27-31.

Dyrenfurth, M. J. (1991). Technological literacy synthesized. In M. J. Dyrenfurth \& M. R. Kozak (Eds.), Technological literacy (pp. 138-186). Peoria, IL: Glencoe, McGraw-Hill.

Ezziane, Z. (2007). Information technology literacy: Implications on teaching and learning. Educational Technology \& Society, 10(3), 175-191.

Feenberg, A. (1999). Questioning technology. New York, NY: Routledge. 
Feenberg, A. (2006). What is philosophy of technology? In J. R. Dakers (Ed.), Defining technological literacy: Towards an epistemological framework (pp. 5-17). New York, NY: Palgrave Macmillan.

Fisher, D. K., Norvell, J., Sonka, S., \& Nelson, M. J. (2000). Understanding technology adoption through system dynamics modelling: Implications for agribusiness management. International Food and Agribusiness Management Review, 3(3), 281-296.

Fonash, S. J. (2001). Education and training of the nanotechnology workforce. Journal of Nanoparticle Research, 3, 79-82.

Gagel, C. W. (2006). Towards an authentic technological literacy. Journal of Industrial Teacher Education, 43(4), 69-75.

Gamire, E., \& Pearson, G. (Eds.). (2006). Tech tally: Approaches to assessing technological literacy. Committee on Assessing Technological Literacy, National Academy of Engineering, National Research Council. Washington, DC: National Academy Press.

Hayden, M. (1989). What is technological literacy? Bulletin of Science, Technology and Society, 119, 220-233.

Hungerford, H., \& Volk, T. (2003). Notes from Harold Hungerford and Trudi Volk. Journal of Environmental Education, 43(2), 4-6.

Ihde, D. (1990). Technology and the lifeworld: From garden to earth. Bloomington, IN: Indiana University Press.

ITEA. (2000). Standards for technological literacy: Content for the study of technology. Reston, VA: International Technology Education Association (ITEA).

Jenkins, E. W. (1997). Technological literacy: Concepts and constructs. Journal of Technology Studies, 23(1), 2-5.

Kahn, R., \& Kellner, D. (2005). Reconstructing technoliteracy: A multiple literacies approach. E-Learning, 2(3), 238-251.

Kuzma, J., Romanchek, J., \& Kokotovich, A. (2008). Upstream oversight assessment for agrifood nanotechnology: A case studies approach. Risk Analysis, 28(4), 1081-1098.

Lewis, T., \& Gagel, C. (1992). Technological literacy: A critical analysis. Journal of Curriculum Studies, 24(2), 117-138.

Leydesdorff, L., \& Etzkowitz, H. (1998). Triple Helix of innovation: Introduction. Science and Public Policy, 25(6), 358-364.

Leydesdorff, L., \& Etzkowitz, H. (2003). Can 'the public' be considered as a fourth helix in universityindustry-government relations? Report on the Fourth Triple Helix Conference, 2002. Science and Public Policy, 30(1), 55-61.

Liddament, T. (1994). Technological literacy: The construction of meaning. Design Studies, 15(2), 198-213.

Mehta, M. D. (2002). Regulating biotechnology and nanotechnology in Canada: A Post-normal science approach for inclusion of the fourth Helix. A paper presented at the International Workshop on Science, Technology and Society: Lessons and Challenges. Singapore: National University of Singapore.

NCES (2004). 2003 National Assessment of Adult Literacy (NAAL)-State and county estimates of low literacy. National Center for Education Statistics (NCES), Institute of Education Sciences. Washington, DC: U.S. Department of Education.

NNI (2000). National Nanotechnology Initiative: The Initiative and Its Implementation Plan. National Science and Technology Council Committee on Technology, Subcommittee on Nanoscale Science, Engineering and Technology, National Nanotechnology Initiative (NNI), Washington, DC http://www.nano.gov/html/res/nni2.pdf. Accessed on: March 17, 2010.

NNI (2009). Nanotechnology: Big things from a tiny world. The National Nanotechnology Initiative http://www.nano.gov/html/society/Education.html Accessed on: February 28, 2010.

NSB (2006). America's pressing challenge-building a stronger foundation: A companion to the Science and Engineering Indicators 2006. National Science Board (NSB). Arlington, VA: National Science Foundation.

NSB (2010). Science and Engineering Indicators: 2010. National Science Boards (NSB). Arlington, VA: National Science Foundation, NSB 10-01.

Pearson, G., \& Young, A. T. (Eds.). (2002). Technically speaking: Why all Americans need to know more about technology. Committee on Assessing Technological Literacy, National Academy of Engineering, National Research Council. Washington DC: National Academy Press.

PEN (2010). Introduction to Nanotechnology. Project on Emerging Nanotechnologies (PEN). Woodrow Wilson International Centre for Scholars. Washington, DC: Pew Charitable Trusts.

Petrina, S. (2000). The politics of technological literacy. International Journal of Technology and Design Education, 10(2), 181-206. 
RCUK (2010). Nanoscience through engineering to application. The Research Councils UK (RCUK). Swindon, UK: Engineering and Physical Sciences Research Council (EPSRC). http://www.rcuknano. org.uk.

RNCOS Consulting (2010). Nanotechnology Market Forecast to 2013. Market Research Consultancy Services. Rockville, MD: MarketResearch.com.

Roco, M. C., \& Bainbridge, W. S. (eds) (2003). Converging technologies for improving human performance: Nanotechnology, biotechnology, information technology and cognitive science. Doredrecht, Boston: Kluwer Academic Publishers (Springer).

Romig, A. D., Jr., Baker, A. B., Johannes, J., Zipperian, T., Eijkel, K., Kirchhoff, B., et al. (2007). An introduction to nanotechnology policy: Opportunities and constraints for emerging and established economies. Technological Forecasting and Social Change, 74(9), 1634-1642.

Rose, L., Gallup, A., Dugger, W., \& Starkweather, K. (2004). The second instalment of the ITEA/Gallup Poll and what it reveals as to how Americans think about technology. A Report of the Second Survey Conducted by the Gallup Organization for the International Technology Education Association (ITEA). http://www.iteaconnect.org/TAA/PDFs/GallupPoll2004.pdf. Accessed on: April 18, 2010.

Schummer, J. (2004). Multidisciplinarity, interdisciplinarity, and patterns of research collaboration in nanoscience and nanotechnology. Scientometrics, 59(3), 425-465.

Selfe, C. L. (1999). Technology and literacy in the twenty-first century: The importance of paying attention. Carbondale, IL: Southern Illinois University Press.

Stevens, S., Shin, N., Delgado, C., Krajcik, J., \& Pellegrino, J. (2007). Using learning progressions to inform curriculum, instruction and assessment design. Paper presented at the annual meeting of the National Association for Research in Science Teaching, New Orleans, Louisiana.

Thomas, L. G., \& Knezek, D. G. (1995). Technology literacy for the nation and for its citizens. Washington, DC: International Society for Technology in Education.

Todd, R. D. (1991). The natures and challenges of technological literacy. In M. J. Dyrenfurth \& M. R. Kozak (Eds.), Technological literacy (pp. 10-27). Peoria, IL: Glencoe, McGraw-Hill.

Toumey, C., \& Baird, D. (2006). Building nanoliteracy in the university and beyond. Nature Biotechnology, 24(6), 721-722.

Waetjen, W. B. (1993). Technological literacy reconsidered. Journal of Technology Education, 4(2), 5-11.

Waks, L. J. (2006). Rethinking technological literacy for the global network era. In J. R. Dakers (Ed.), Defining technological literacy: Towards an epistemological framework (pp. 275-295). New York, NY: Palgrave Macmillan.

White, S., \& Dillow, S. (2005). Key concepts and features of the 2003 National Assessment of Adult Literacy. National Centre for Education Statistics (NCES 2006-471). Institute of Education Sciences. Washington, DC: U.S. Department of Education.

Yawson, R. M. (2009). The ecological system of innovation: A new architectural framework for a functional evidence-based platform for science and innovation policy. In K. R. E Huizingh, S. Conn, M. Torkkeli, \& I. Bitran, (Eds.), The future of innovation. Proceedings of XX ISPIM 2009 conference. Vienna, Austria: Wiley Higher Education.

Yawson, R. M. (2010). Skill needs and human resource development in the emerging field of nanotechnology. Journal of Vocational Education \& Training, 62(3), 285-296.

Yawson, R. M., \& Kuzma, J. (2010). Systems mapping of consumer acceptance of agrifood nanotechnology. Journal of Consumer Policy, 33(4), 299-322. 